\title{
Espírito e liberdade na obra de Viktor Frankl
}

\author{
Ivo Studart Pereira* \\ Universidade Federal do Ceará, Departamento de Filosofia. Fortaleza, CE, Brasil
}

\begin{abstract}
Resumo: $\mathrm{O}$ presente trabalho tem o propósito de expor e analisar o primeiro dos três fundamentos básicos relativos à logoterapia de Viktor Frankl: o problema da liberdade humana. Iniciamos nosso esforço argumentativo por meio da discussão a respeito do significado da categoria "espírito" enquanto conceito antropológico e sua intrínseca relação com o tema da liberdade humana. Num segundo momento, discute-se como essa visão de liberdade se relaciona com aquilo que Frankl entendeu como os três complexos básicos de determinação aos quais o homem está submetido sob a forma dos "destinos" biológico, psicológico e sociológico. Analisamos o argumento afirmativo da liberdade espiritual no contexto de cada um desses domínios.
\end{abstract}

Palavras-chave: logoterapia, Viktor Frankl, liberdade, espírito, determinismo.

O pensador austríaco Viktor Emil Frankl (1905-1997) foi o criador da chamada logoterapia, abordagem psicoterápica situada na tradição humanista e existencial e também conhecida como a terceira escola vienense de psicoterapia, precedida pela psicanálise freudiana e pela psicologia individual de Alfred Adler. No presente trabalho procuraremos analisar o primeiro dos três fundamentos teóricos do sistema conceitual da logoterapia tais como Frankl os concebeu: 1) a liberdade da vontade, 2) a vontade de sentido e 3) o sentido da vida (Frankl, 2011, p. 7). Trata-se de um ponto de partida que reputamos relevante no sentido de uma compreensão satisfatória do pensamento frankliano, já que, preferencialmente, é por meio de uma discussão preliminar a respeito da liberdade espiritual que se podem clarificar apropriadamente os demais conceitos fundamentais do sistema. Nosso percurso argumentativo se iniciará através da discussão a respeito do significado da categoria "espírito" enquanto conceito antropológico no quadro teórico da logoterapia e sua relação com o problema da liberdade humana. Num segundo momento, discutiremos como essa visão de liberdade se relaciona com os três complexos básicos de determinação a que o homem está submetido sob a forma dos "destinos" biológico, psicológico e sociológico.

Antes de abordarmos mais diretamente o conceito de espírito na logoterapia, devemos ter em mente que, em tal escola psicoterápica, o homem é concebido como a síntese de três categorias constitutivas fundamentais: corpo, psiquismo e espírito. Frankl organizou tais categorias sob a forma de um arranjo dialético de inspiração geométrica, que batizou de "ontologia dimensional". No presente artigo, no intuito de nos mantermos fiéis aos objetivos do trabalho, não nos ocuparemos de detalhar esse modelo de organização, mas é importante frisar que este estará pressuposto ao

* Autor correspondente: ivusp@yahoo.com.br longo de toda a exposição. A noção de "espírito" já está intencionalmente presente na formação etimológica do termo "logoterapia". O próprio Frank1 sempre definiu seu projeto terapêutico como uma "psicoterapia em termos espirituais" (Frankl, 2003). O radical grego logos foi utilizado por ele a fim de tomar para seu sistema a peculiar polissemia do termo, que pode ter tanto a acepção de "espírito" quanto a de "sentido" (Frankl, 1988, p. 18). Aqui já cabe esclarecer que o conceito de espírito (Geist, no original em alemão), na obra de Frankl, não possui qualquer acepção de cunho religioso, como geralmente ocorre no contexto dos usos da mencionada palavra em inglês ou português. Nesse sentido, essa é a razão pela qual o autor foi gradativamente substituindo o termo por dimensão "noológica" ou "noética" a partir do vocábulo grego "noûs", que, como veremos, é também uma fonte semântica tradicional da noção de espírito:

O que nós compreendemos como dimensão noológica se refere a uma conceituação antropológica, muito mais do que teológica. O mesmo também vale para o "logos, no contexto do termo "logoterapia. Além de denotar "sentido", "logos" aqui significa 'espírito' - mas, novamente, sem qualquer conotação religiosa primária. Aqui, "logos" significa a humanidade do ser humano e o sentido de ser humano! (Frankl, 1988, p. 17, tradução nossa)

Antes de, propriamente, nós nos debruçarmos sobre a referida categoria na letra de Frankl, vale, aqui, recorrermos à rica obra sobre Antropologia Filosófica de Vaz (2001) de modo breve, a fim de que esbocemos uma retrospectiva histórica das diferentes noções sobre o que já se concebeu filosoficamente a respeito da ideia de espírito. Primeiramente, vê-se o espírito enquanto pnêuma, que tem seu eixo metafórico na noção de "sopro vital": vida em 
organização superior, princípio organizador de vida. Como noûs, vê-se o espírito enquanto intelecto, inteligência, forma mais elevada da produção de conhecimento. Já como logos, a categoria assume ares de atividade ordenadora da razão universal, da palavra, meio através do qual o espírito também se manifesta por excelência. Enquanto synesis, vemos a consciência de si mesmo, a volta sobre si mesmo, partindo da exterioridade da Natureza:

Segundo esses quatro temas fundamentais que se entrelaçam para constituir o núcleo conceptual da noção de espírito, podemos enumerar as propriedades essenciais desse núcleo constituindo a estrutura noético-pneumática do homem, ou seja, a sua estrutura enquanto inteligência e liberdade. Desde o ponto de vista da inteligência, o homem, ser espiritual, deve ser definido ser-para-a-verdade; desde o ponto de vista da liberdade, deve ser definido ser-para-o-bem. (Vaz, 1991, p. 212)

Compreendendo o espiritual como inteligência e liberdade, o filósofo alemão Max Scheler (1874 - 1928), pensador que influenciou Frankl mais decisivamente neste campo, corrobora a visão da tradição e formula, por meio da categoria "espírito", o cerne de sua antropologia filosófica, encontrando, a partir de tal princípio, aquilo que chamou de "posição peculiar" do homem:

Se colocarmos no ápice do conceito de espírito uma função particular de conhecimento, a espécie de conhecimento que só ele pode dar, então a determinação fundamental de um ser espiritual, como quer que este venha a ser constituído psicologicamente, é o seu desprendimento existencial do orgânico, sua liberdade, sua separabilidade - ou ao menos a separabilidade de seu centro existencial - ante os laços, a pressão e a dependência do orgânico, da 'vida' e de tudo o que pertence à vida - portanto, também de sua própria "inteligência" pulsional. (Scheler, 2003, p. 36)

Scheler fala do "desprendimento" e da "separabilidade" que o espírito confere à condição humana. No homem, como ser espiritual, trata-se da capacidade de distanciamento de sua conformação biológica e de suas determinações psíquicas; em suma, da possibilidade mesma de objetivar, conscientemente, tais imposições, e de escolher uma resposta livre frente a elas. O núcleo conceitual da noção de espírito na logoterapia parte de uma ratificação e de um particular desenvolvimento da concepção antropológica de Scheler. Para Frankl, o "espiritual" no homem designa, ontologicamente, aquela dimensão de lucidez e autoconsciência que pode confrontar-se com toda gama de condicionamentos - sejam estes sociológicos, biológicos ou psíquicos -, desvelando a capacidade humana de decisão e autoconfiguração: "Por definição, o espiritual é só o livre no homem. Partindo de um princípio, chamamos 'pessoa' só aquilo que pode comportar-se livremente, sejam quais forem as circunstâncias" (Frankl, 1995, p. 96). A dimensão espiritual empodera o homem com a capacidade de tornar inteligíveis as dinâmicas de determinação e controle de que ele participa, transformando o que a princípio mostra-se como automatismo em autonomia. Encontramos, aí, a dimensão distintiva e essencial do ser do homem, fonte dos fenômenos tipicamente humanos. No entanto, na prática, perante que determinações ocorre essa liberdade? Isto é, que limites e imposições são estes, que condicionam as ações humanas e das quais podemos ter consciência e liberdade por meio de nossa dimensão espiritual?

Segundo Frankl, o homem se confronta com três formas básicas de influência condicionante sobre sua vontade livre: os instintos e o caráter (condicionamentos psíquicos); a hereditariedade e o corpo (condicionamentos biológicos); e o meio ambiente físico e social (condicionamentos sociológicos). Frankl batizou tais complexos condicionantes de destino psicológico, destino biológico e destino sociológico (Frankl, 2003, pp. 125-137). Cabe lembrar que, com o termo "destino" (Schicksal), a logoterapia entende designar "o que há de fatal" (Schicksalhafte) na vida humana: "denominamos destino exatamente aquilo sobre o que não temos influência, aquilo que essencialmente escapa ao poder de nossa vontade" (Frankl, 1981, p. 95). A liberdade humana não é uma liberdade absoluta, solta, "flutuante"; ela só existe dialeticamente, perante as formas concretas de destino: "toda a liberdade humana depende do que há de fatal, na exata medida em que só neste elemento e a ele aderindo pode desenvolver-se" (Frankl, 2003, p. 123). Para Frankl, a relação dialética entre destino e liberdade é marcada pela atitude pessoal diante do imutável, defendendo-se a ideia de um homem "co-plasmador" (Lukas, 1989, p. 39) de seu destino, ao invés de meramente vítima deste.

Quanto ao primeiro “destino", Frankl nega o pandeterminismo instintivo do homem, isto é, a ideia de que, em última instância, todas as ações e esforços humanos seriam fruto direto de seus apetites instintuais, dos quais o homem seria um mero resultado. $\mathrm{O}$ psiquiatra vienense procede com essa negação sem, contudo, negar a irrecusável realidade pulsional de que o ser humano faz parte. Sua fórmula, nesse sentido, parece ser: "O homem possui instintos, mas os instintos não possuem o homem” (Frankl, 1990, p. 117). A afirmação dos instintos não contradiz a liberdade humana, pois esta pressupõe a possibilidade de negação daqueles. Em seu funcionamento psicológico-pulsional, fica evidenciado que, no homem, os instintos nunca aparecem "em si". Frankl defende uma espécie de a priori espiritual que pré-configura toda atividade instintiva. A tomada de posição espiritual se sobrepõe a toda instintividade, de modo que "os instintos são sempre dirigidos e marcados a partir da pessoa; os instintos sempre são personalizados" (Frankl, 1995, p. 90) e nunca ocorrem sem a possibilidade de autoconsciência emanada da dimensão espiritual.

Essa lacuna, esse intervalo que "descola" o ser humano da facticidade de sua condição instintiva constitui 
uma faceta de sua liberdade espiritual, de modo que aí logo se mostra a distinção básica entre homem e animal: enquanto o animal "é" seus instintos (Frankl, 1990, p. 118), a instintividade do homem sempre está dialeticamente incluída em sua espiritualidade. $O$ animal é idêntico a seus instintos exatamente porque não haveria uma vontade livre e autoconsciente que se sobrepusesse ou perdurasse às mudanças de seus impulsos instintuais. Isto é, o animal está sempre preso a um estrito esquema cognitivo-comportamental em que os instintos o impelem a modificar o meio de alguma forma, e o meio modificado aponta ao animal como reagir. $\mathrm{O}$ animal, por mais evoluído que seja, não tem a capacidade de distanciar-se desse esquema, decidindo-se sobre a realização ou não de seus ditames pulsionais, enquanto no homem, "entre estímulo e resposta, existe um espaço. Nesse espaço, encontra-se o poder de escolher nossa resposta. Em nossas respostas, residem nosso crescimento e nossa felicidade" (Pattakos, 2004, p. 8). É nesse sentido que Scheler afirma que um animal sempre chega, por assim dizer, a um lugar "diverso do que ele originariamente 'queria' chegar", interpretando, através desse raciocínio, o aforismo nietzschiano segundo o qual "o homem é o animal que pode prometer" (Scheler, 2003, p. 40). O animal é consciente, na medida em que "vê", mas não é autoconsciente, na medida em que não "sabe" que vê. Autoconsciência - a capacidade de reflexão - é uma característica essencial do homem, entendido enquanto ser espiritual:

Por força de seu espírito, o ser que denominamos "homem" não consegue apenas ampliar o meio ambiente até o interior da dimensão da mundaneidade e objetivar resistências, mas ele também consegue - e isto é o mais espantoso - objetivar uma vez mais a sua própria constituição fisiológica e psíquica $\mathrm{e}$ cada vivência singular psíquica, cada uma de suas funções vitais mesmas. Apenas por isto ele pode modelar livremente a sua vida. $\mathrm{O}$ animal ouve e vê - mas sem saber que ouve e vê. A psiche do animal funciona, vive - mas o animal não é nenhum possível psicólogo ou fisiólogo! (Scheler, 2003, p. 39)

É nesse contexto que, na concepção da logoterapia, "não só quando os instintos estão inibidos, mas também quando eles se desembaraçam, o espírito sempre age, sempre interfere, ou permanece em silêncio no interior" (Frankl, 1995, p. 91). Logo, sempre que se manifesta no homem uma "atividade instintual desintegrada", já não se trata de um homem são (Frankl, 1990, p. 32). Instintividade e liberdade, como vimos, encontram-se numa relação de necessidade recíproca: "no homem, não há instintos sem liberdade, nem liberdade sem instintos" (Frankl, 1995, p. 32). Por força de sua dimensão espiritual, toda diretriz instintiva é perpassada por uma zona de liberdade.

Ainda sobre o tema da liberdade espiritual frente à constituição psíquica, Frankl não concorda com a acusação de que a psicanálise seja pansexualista (Frankl, 2003, p. 19), mas reconhece nela um pressuposto bem mais "errôneo e perigoso": o pandeterminismo, enquanto visão de ser humano que "descarta a sua capacidade de tomar uma posição frente a condicionantes quaisquer que sejam" (Frankl, 1985, p. 112). Frankl enxerga na antropologia implícita da psicanálise um modelo mecânico-homeostático de redução de tensão, no qual o princípio da realidade estaria apenas a serviço do princípio do prazer, modulando-o na vida social, mas sempre com o interesse de garanti-lo (Frankl, 1988, p. 32). A tese psicanalítica de que o ego, portanto, derivaria do id e a ele estaria submetido é contestada por Frankl, para quem o id seria sempre o id de um ego, que, por sua vez, não é apenas a resultante de uma soma de pressões, como, metaforicamente, num paralelograma de forças na Física. O poder de decisão do ego é ilustrado por Frankl por meio da seguinte metáfora:

O ego "quer". O id "impulsa". Mas nunca o ego é absolutamente "impulsado". Velejar não é simplesmente deixar o bote correr ao sabor do vento que o 'impulsa'; a arte de velejar começa, antes, pelo contrário, precisamente quando se está em condições de imprimir à força do vento a direção desejada, podendo-se, inclusive, dirigir a embarcação contra o vento. (Frank1, 2003, p. 131)

Isto é, em sua condição psíquica, o homem não decide como os instintos aparecerão perante sua vontade livre, assim como o velejador não tem o poder de escolher como o vento se mostrará a ele. O que o homem pode fazer é decidir, livremente, por sobre aquilo que lhe ocorreu enquanto fato psicológico, configurando o modo por meio do qual administrará a influência da energia pulsional em sua vida, assim como o velejador, sabendo aonde quer ir, administra o vento a seu favor. Nesse sentido, quanto à questão do controle do $i d$ pelo ego, Frankl adverte para que não se coloque num mesmo plano a distinção entre poder e força. Ilustra o argumento do controle apriorístico do ego sobre o id com outra metáfora: essa relação seria como a de um juiz senil que condena um réu forte e musculoso. Isto é, questionar o poder do juiz, nesse caso, seria o mesmo que confundir o "poder judicial" com "poder físico". Há de se distinguir, como o fez Martin Buber (citado por Frankl, 1978, p. 158), entre "força" e "capacidade de pôr forças em movimento", o que seria o característico da atividade espiritual:

É impossível, por conseguinte, conceber o ego como fundamentado nos impulsos. O que, entretanto, não exclui que em todo esforço pelos valores se encaixa algo de pulsional, já que, como dissemos, os impulsos atuam como energia alimentadora. A energia, todavia, é mobilizada pelo ego, que pode e deve dela dispor. A energia pulsional que entra na dinâmica do anseio pelos valores terá sido mobilizada por uma instância não-pulsional, cuja realidade é comprovada justamente através dessa mobilização. (Frankl, 1978, p. 209) 
Frankl reconhece que, na prática, o homem, frequentemente, não "é" livre de seus instintos. No entanto, facultativamente, o ser humano é e permanece livre, de modo que, sempre que assim não parecer, é porque renunciou à própria liberdade. Sempre que age como "se fosse conduzido" é porque se deixou conduzir, já que "ele pode muito bem entregar-se a seus instintos, mas mesmo esta entrega é de sua responsabilidade" (Frankl, 1978, p. 159). Essa faculdade, no entanto, é o que faz toda a diferença, já que o que realmente importa não são os condicionamentos psicológicos em si, mas sempre a atitude que tomamos diante deles: "É a capacidade de posicionar-se dessa maneira que faz de nós seres humanos" (Frankl, 1988, p. 17). Cumpre frisar que a logoterapia não nega, portanto, os instintos em si - tanto do ponto de vista ôntico, quanto do ponto de vista ético. Quando for oportuno, o homem pode e deve afirmar seus instintos. No entanto, como já dissemos, não se poderia afirmar algo sem que antes se pudesse ter tido a oportunidade de negá-lo: "Importa afirmar os instintos, mas não afirmá-los à custa da liberdade, mas sempre no contexto, e em nome da liberdade" (Frankl, 1988, p. 158). A logoterapia também se esforça em combater as leituras antropológicas psicologistas, na medida em que afirma a liberdade humana em face de outro condicionamento psíquico: o do caráter, ou tipologia psicológica.

O indivíduo neurótico, do ponto de vista da logoterapia, seria, essencialmente, aquela pessoa que distorce a interpretação da própria existência, transformando-a de um "poder-vir-a-ser-sempre-de-outra-forma" num "deverser-assim-e-não-de-outra-forma” (Frankl, 1995, p. 100). Frankl ressalta a frequência com que se escuta de tais indivíduos o apelo a um determinado caráter ou tipo psicológico para justificar sofrimentos e atitudes e afirma que, no mesmo instante em que esse apelo toma lugar, o indivíduo busca um bode expiatório, um pretexto para eximir-se de sua liberdade de tomar posição diante de sua estrutura psíquica, a qual não o determina completamente, apenas o condiciona. Aquilo que o caráter condiciona, por conseguinte, "em caso nenhum é o decisivo; o decisivo, em última instância, é sempre a tomada de posição da pessoa. Portanto, 'em última instância', a pessoa (espiritual) decide sempre acima do caráter (psíquico)" (Frankl, 1995, p. 98). A pessoa espiritual é livre e encontra-se sempre confrontada com seu caráter psíquico, que constitui um desses complexos de condicionamento perante o qual ela é livre: "O caráter é criado; a pessoa é criativa” (Frankl, 1978, p. 161). Em suma, a tese de Frankl é a de que a liberdade humana se afirma diante de sua estrutura psicológica, especialmente ainda quando esta reflete sofrimento psíquico, já que:

no fatalismo neurótico, o que há é um livre-arbítrio encoberto: o homem neurótico barra a si próprio o caminho para suas próprias possibilidades; atravessa-se a si próprio no caminho que o levaria ao seu "poder-ser". Assim, deforma sua vida e furta-se à "realidade do devir", em vez de a executar. (Frankl, 2003, p. 123)
No que diz respeito ao destino biológico, o pai da logoterapia defende a tese de que a liberdade humana persiste, inclusive, diante da constituição genética do indivíduo. Frankl, dos vários exemplos que cita, retoma o resultado dos experimentos do psiquiatra Johannes Lange (1891-1938 - referência de Frankl à obra Verbrechen als Schicksal: Studien an kriminellen Zwillingen) com gêmeos monozigóticos, os quais revelaram vários casos relevantes ao tema em questão, como aquele em que um dos irmãos se tornara um astuto criminoso, enquanto o outro viera a ser um criminalista igualmente astucioso. O que se revelou, aí, foi a noção a respeito de como podem ser diferentes as vidas construídas por sobre uma constituição genética idêntica. Ora, a predisposição inata, a astúcia, está presente em ambos os irmãos, mas em si mesma mostrou-se neutra quanto aos rumos que cada um tomou - rumos esses não determinados pela constituição genética em si, mas sim pelas decisões diferentes que ambos vieram a tomar. Para além desse condicionamento, existe a liberdade espiritual do homem, capacidade esta que "o eleva e o projeta além de suas contingências" (Frankl, 1990, p. 142). Para Frankl, a carga genética determina unicamente a condição psicofísica do homem. Os cromossomos herdados dos pais determinam o homem naquilo que ele "tem", mas nunca naquilo que "e’".

Cada ser humano que nasce é um novum absoluto: a existência espiritual é intransmissível, jamais podendo ser hereditária. O que se passa de pais a filhos é sempre uma "possibilidade psicofísica", uma potência psicofísica; o que se transmite é "apenas o espaço psicofísico de ação", mas nunca a liberdade espiritual que se relaciona com esse espaço. Numa palavra: "o que é transmissível são as fronteiras psicofísicas, não o que fica entre elas. São as pedras da construção, jamais o mestre-de-obras" (Frankl, 1978, p. 126). É nesse sentido que Frankl assevera que a relação existente entre a pessoa espiritual e seu organismo biológico é de natureza expressivo-instrumental: o espírito organiza e instrumenta o organismo psicofísico; a pessoa espiritual "o forma 'para si', na medida em que o faz utensílio, órgão, instrumentum" (Frankl, 1978, p. 117). O destino biológico se mostra, diante da liberdade humana, como puro "material a configurar". O portador inalienável de tal destino - algo que, obviamente, todos somos - confere sentido a essa forma de determinação ao integrá-la na "estrutura histórica e biográfica de sua vida" (Frankl, 2003, p. 129). O pensador vienense certamente concordaria com o célebre subtítulo promocional da intrigante produção cinematográfica "Gattaca", de Andrew Niccol, que afirma: "não há gene para o espírito humano" (Niccol, 1997).

No que diz respeito ao determinismo do meio, o terceiro dos "destinos" debatidos por Frankl, a logoterapia sustenta que, diante dos condicionamentos irrecusáveis que o ambiente impõe ao homem, em última instância, o que realmente importa é o que o homem faz do próprio meio, isto é, a atitude que o homem toma diante dos condicionamentos ambientais. Dos diversos exemplos que cita, talvez aquilo que Frankl chamou de experimentum crucis, isto é, sua experiência de três anos como prisioneiro nos campos de concentração da Segunda Guerra Mundial, venha a 
servir de dado mais eloquente para o argumento da logoterapia sobre o tema: "Neles [nos campos de prisioneiros], era possível ver o 'poder de decisão' do espiritual: enquanto um se deixava transformar num 'patife', outro - ceteris paribus - se tornava um 'santo"' (Frankl, 1978, p. 133). O questionamento fundamental parece ser: o homem ainda arcaria com a responsabilidade por aquilo que o campo de concentração "fez" dele? Frankl não hesita em responder que sim. Perguntando a si mesmo se em tais condições ainda haveria espaço para algo como "decisão", responde: "Não nos admira; pois 'existência' - para cuja nudez e desproteção o homem foi reconduzido - nada mais é do que decisão" (Frankl, 1981, p. 66). Mesmo num ambiente socialmente tão adverso e determinado ao pior, ainda restava ao homem aquela "derradeira liberdade com que, de um modo ou de outro, consegue ele configurar sua existência":

Há exemplos bastantes - freqüentemente heróicos que demonstram como o homem, mesmo em campos deste tipo, "também pode ser-diferentemente", não tendo que sucumbir às leis, à primeira vista, onipotentes, do campo de concentração, que lhe impõem uma deformação anímica. Antes pelo contrário, está demonstrado que, quando alguém assume as propriedades caracterológicas típicas dos presidiários dos campos. ... e, portanto, sempre que alguém sucumbe às forças de seu meio-ambiente social que lhe modelam o caráter - é precisamente porque antes se deixou decair no aspecto espiritual. (Frankl, 2003, p. 141)

Disso depreende-se que um mesmo ambiente pode gerar as mais diferentes reações, isto é, um meio idêntico vem a possibilitar as atitudes mais diversas face a ele. Por conta de sua condição espiritual, ainda que confrontado pelas situações mais adversas, o homem pode posicionar-se diante desses condicionamentos, distanciar-se deles e decidir-se sobre si mesmo. A liberdade, nesse sentido, não é algo que eu venha a "perder" - assim como posso perder qualquer coisa que eu "tenha" -, mas sim algo que "sou" e do qual só posso afastar-me por decisão, quando decido abrir mão de agir livremente: "Não se perde a liberdade de atitude perante uma situação concreta; o que sucede, simplesmente, é que o homem se lhe entrega, numa atitude de desistência" (Frankl, 2003, p. 141). Para Frankl, assim como o animal "é" seus impulsos, o ser humano "é" sua liberdade, na medida em que esta é sua "característica permanente e definitiva", podendo a ela voluntariamente renunciar, mas não perder (Frankl, 1990, p. 118).

Aqui se contextualiza mais uma famosa refutação de Frank1 a Freud, quem teria dito que "diante da fome, as diferenças individuais se apagam. Com o aumento da imperiosa necessidade de alimentação, as diferenças desaparecem e em seu lugar manifestam-se uniformes exigências do instinto insatisfeito" (Freud, citado por Frankl, 1978, p. 178). Para Frankl, que teve a oportunidade de testar pessoalmente essa hipótese, o que ocorre é exatamente o contrário. Nos campos de concentração, a qualidade da decisão de cada um é o que vinha à tona: "santos" e "porcos" se revelavam. Em qualquer dos casos, a fome era sempre a mesma; "os homens é que eram diferentes" (Frankl, 1978, p. 178). Isto é, até numa situação-limite de privação e degradação pôde-se atestar a capacidade de obstinação do espírito humano: "no campo de concentração se pode privar a pessoa de tudo, menos da liberdade última de assumir uma atitude alternativa frente às condições dadas. E havia alternativa!" (Frankl, 1995, p. 66).

Essa mesma liberdade se aplicaria às chamadas "leis sociológicas", as quais, no pensamento de Frankl, nunca atuam passando "por cima dos indivíduos", mas sempre "através deles". A possível validade dessas leis só poderia ser pensada na medida em que os cálculos dissessem respeito à psicologia das massas, o que, ainda assim, só poderia ocorrer na medida em que se pudesse medir algo como um tipo psicológico médio (Frankl, 2003, p. 117). Frankl reconhece a condição do indivíduo na estrutura social, afirmando que a comunidade exerce dois tipos de determinação por sobre ele: o organismo social, como um todo, o condiciona; por outro lado, e simultaneamente, o indivíduo é orientado para se ajustar ao dito organismo. Nessa dupla relação, Frankl distingue duas condições: uma "causalidade social" exercida sobre o indivíduo e a emergência de uma "finalidade social" para este. O pai da logoterapia defende, contudo, que essa causalidade social nunca absorve completamente $o$ indivíduo, por cuja zona de liberdade pessoal qualquer "lei sociológica" tem de passar antes de influenciá-lo. Isto é: "o homem conserva também em face do destino social certa margem de livre possibilidade de decisão, tal como perante o destino biológico ou psicológico" (Frankl, 2003, p. 136).

Cumpre advertir, no entanto, que a logoterapia nunca se mostrou interessada em promover-se enquanto uma “ideologia de auto-redenção" (Lukas, 1989, p. 158). Frankl sabe que a pessoa espiritual é limitada. Essa qualidade de limitação diz respeito ao caráter condicionado do ser humano; o homem só é incondicionado de forma facultativa, pois, de fato, permanece condicionado. Por mais que, constitutivamente, o homem seja um ser espiritual, ele continua sendo um ser limitado: "Daqui já deriva que a pessoa espiritual não é capaz de se impor absolutamente por meio dos estratos psicofísicos" (Frankl, 1995, p. 83). Apenas de maneira limitada, o homem é um ser não-limitado; na verdade, o ser livre do homem, afirma Frankl, não é um fato, mas um "simples facultativum" (Frankl, 1995, p. 99). O homem não tem que fazer sempre o uso do poder de obstinação do espírito, já que, pelo menos, apesar de ele, tantas vezes, imporse, apesar de seus instintos, apesar de sua hereditariedade e apesar de seu meio ambiente, muitas vezes, ele também vem a impor-se graças a seus instintos, à sua hereditariedade $\mathrm{e}$ ao seu meio ambiente (Frankl, 1990, p. 119).

Frankl caracteriza como a "posição natural do homem" essas disposições biológica, psicológica e sociológica do ser humano, posição essa fixada sempre por suas ciências correspondentes, enquanto resultado da soma desses três destinos. Para a logoterapia, no entanto, o homem só começa a ser homem na fronteira em que acaba toda 
a possibilidade de fixar tal posição natural; isto é, o que começa a partir daí, ligando-se à posição natural de um homem, é sua atitude pessoal, sua tomada de posição livre em relação a tais disposições, em qualquer situação:

Pois bem, essa atitude eo ipso já não pode ser objeto de uma das ciências indicadas; ela se subtrai a qualquer abordagem desse tipo, realiza-se numa dimensão à parte. Além disso, tal atitude é essencialmente uma atitude livre; em última instância, é decisão. E, se ampliássemos nosso sistema de coordenadas com a última dimensão possível, então esta consistiria no que sempre é possível, graças à liberdade da atitude pessoal: trata-se da mudança existencial. (Frankl, 1995, p. 93)

Devemos concluir, do que expomos até aqui, que, apesar de reconhecer o amplo nível de influência condicionante das dimensões biológica e psicológica (a que Frankl também se referiu como "disposição vital") e da dimensão sociológica (que Frankl também chama de "situação social"), a logoterapia afirma o princípio da liberdade espiritual como característica constitutiva do ser do homem. Em suma, é por meio de sua dimensão espiritual que o homem pode objetivar as dinâmicas de condicionamento a que está submetido, na medida em que sua autoconsciência o torna livre para decidir, para tomar uma atitude diante das formas de destino que se lhe apresentam. A logoterapia tem como ponto de partida, portanto, a demonstração de que o homem não é "pandeterminado", ou seja, completa e absolutamente determinado pelos fatores vitais e sociais, sendo, no sentido dialético que aqui investigamos, livre deles e responsável por sua autoconfiguração. Frankl busca, nesse esforço, recuperar "a existência humana para o seu nível autêntico, por cima dos condicionamentos biológicos, psicológicos ou sociológicos" (Frankl, 1978, p. 270). Cremos, por fim, ter caracterizado, minimamente, o fundamento de entrada do sistema teórico da logoterapia, procurando prover ao leitor os pressupostos conceituais necessários a uma melhor compreensão dos consequentes debates centrais do pensamento Frankliano, tanto em seus aspectos técnicos, quanto em suas particularidades éticas.

\section{Viktor Frankl on spirit and freedom}

Abstract: This paper aims to expose and analyze the first of the three conceptual foundations relating to the logotherapy of Viktor Frankl: the issue of human freedom. The argumentative effort is initiated by the discussion regarding the meaning of the "spirit" category as an anthropological concept and its intrinsic relation to the theme of human freedom. Secondly, it is discussed how this conception of freedom relates to what Frankl conceived as the three basic complexes of determination to which man is subjected under the form of biological, psychological and sociological "destinies". The affirmative argument of spiritual freedom in the context of each of these areas is analyzed.

Keywords: logotherapy, Viktor Frankl, freedom, spirit, determinism.

\section{Liberté et esprit dans l'oeuvre de Viktor Frankl}

Résumé: Le présent travail a pour but d'exposer et analyser le premier des trois fondements basiques relatifs à la logothérapie de Viktor Frankl: le problème de la liberté humaine. J'introduis mon argumentation par la discussion à propos de la signification de la catégorie " esprit » comme concept anthropologique, et son intrinsèque relation avec le thème de la liberté humaine. À un deuxième moment, je discute de quel façon cette vision de liberté se rapport à ce qui Frankl a compris comme les trois complexes basiques de détermination auxquels l'homme est soumis, sous la forme des « destins » biologique, psychologique et sociologique. J'analysons l'argument affirmatif de la liberté spirituelle dans le contexte de chacun de ces domaines.

Mots-clés: logothérapie, Viktor Frankl, liberté, esprit, déterminisme.

\section{Espíritu y libertad en la obra de Viktor Frankl}

Resumen: El presente trabajo tiene como objetivo exponer y analizar el primero de los tres fundamentos básicos relativos a la logoterapia de Viktor Frankl: el problema de la libertad humana. Iniciaré mi esfuerzo argumentativo por medio de la discusión con respecto al significado de la categoría de "espíritu" mientras concepto antropológico, y su intrínseca relación con el tema de la libertad humana. En un segundo momento, discutiré como esta visión de libertad se refiere al que Frankl entendió como los tres complejos básicos de determinación a que el hombre está sometido, sobre la forma de los "destinos" biológicos, psicológicos y sociológicos. Analizaré el argumento afirmativo de la libertad espiritual en el contexto de cada uno de estos dominios.

Palabras clave: logoterapia, Viktor Frankl, libertad, espíritu, determinismo. 


\section{Referências}

Niccol, A. (Diretor), DeVito, D., Shamberg, M., \& Sher, S. (Produtores). (1997). Gattaca [Filme]. EUA: Sony Pictures.

Frankl, V. E. (1978). Fundamentos antropológicos da psicoterapia (R. Bittencourt, trad.). Rio de Janeiro, RJ: Zahar.

Frankl, V. E. (1981). A questão do sentido em psicoterapia (J. Mitre, trad.) Campinas, RJ: Papirus.

Frankl, V. E. (1985). Em busca de sentido (W. Schlupp \& C. Aveline, trad.). Petrópolis, RJ: Vozes.

Frankl, V. E. (1988). The will to meaning. Nova York, NY: Meridian Books.

Frankl, V. E. (1990). Psicoterapia para todos: uma psicoterapia coletiva para contrapor-se à neurose coletiva (A. Allgayer, trad.). Petrópolis, RJ: Vozes.

Frankl, V. E. (1995). Logoterapia e análise existencial: textos de cinco décadas (J. Santos, trad.). Campinas, SP: Psy II.

Frankl, V. E. (2003). Psicoterapia e sentido da vida (A. M. de Castro, trad.). São Paulo, SP: Quadrante.
Frankl, V. E. (2011). A vontade de sentido (I. S. Pereira, trad.). São Paulo, SP: Paulus.

Lukas, E. (1989). Logoterapia: a força desafiadora do espírito (J. de S. Porto, trad.). São Paulo, SP: Loyola.

Pattakos, A. (2004). Prisioneiros de nossos pensamentos: os princípios de Viktor Frankl para a descoberta de sentido na vida e no trabalho. (P. Libanio, trad.). Rio de Janeiro, RJ: Rocco.

Scheler, M. (2003). A posição do homem no cosmos. (M. A. Casanova, trad.). Rio de Janeiro, RJ: Forense Universitária.

Vaz, H. C. L. (1991). Antropologia filosófica I. São Paulo, SP: Loyola.

Vaz, H. C. L. (1992). Antropologia filosófica II. São Paulo, SP: Loyola.
Recebido: 30/04/2014

Revisado: 18/09/2014

Aceito: 28/09/2014 